non-cancer $10 \mathrm{mg}$; Oxycodone - cancer $20 \mathrm{mg}$, noncancer $10 \mathrm{mg}$.

Conclusion(s) The use of CSCI is around half of that in 2008/9. Type of drugs administered was similar in both groups. Dose of opiates for non-cancer patients was lower on average.

\section{P 002 THE USE OF MEDICATIONS IN THE LAST 24 HOURS OF LIFE IN THE ACUTE HOSPITAL SETTING-A DESCRIPTIVE COMPARISON OF CANCER AND NON CANCER PATIENTS USING DATA FROM THE NATIONAL CARE OF THE DYING AUDIT HOSPITALS -ENGLAND (NCDAH) 2013/14}

K Tewani, ${ }^{1}$ H Mulholland, ${ }^{1}$ M Gambles, ${ }^{1}$ D Lowe, ${ }^{2}$ J Husk, ${ }^{2}$ K Stewart, ${ }^{2}$

J Ellershaw'. 'Marie Curie Palliative Care Institute Liverpool (MCPCIL), University of Liverpool; ${ }^{2}$ Clinical Effectiveness and Evaluations Unit (CEEU), Royal College of Physicians (RCP)

10.1136/bmjspcare-2014-000838.5

Introduction International consensus exists for the use of 4 key drugs pertinent to care of the dying and the use of CSCI is advocated, where appropriate, to support patient comfort. In the NCDAH 2008/09, $54 \%$ of 3,893 patients had CSCI prescribed; of these 1026 were cancer patients (67\% of all cancer patients) and 1080 were non-cancer patients $(46 \%$ of all noncancer patients).

Aim(s) and method(s) Aim: to explore medications and dosages prescribed via CSCI in the last 24 hours of life for cancer and non-cancer patients.

Using clinical data from 6,580 cases (from 149 sites) reported within the NCDAH 2013/14, combinations and doses of drugs given via CSCI in the last 24 hours of life were analysed descriptively.

Results CSCI prescribed for 1,850 (28\%) patients. 722 were cancer patients; 1128 were non-cancer patients (representing $46 \%$ and $22 \%$ of all cancer and noncancer patients, respectively). Non-cancer patients were older (83 vs 74) and had recognition of 'dying' earlier (75 hours vs 62 hours prior to death). The 4 key drugs were regularly prescribed. Most (both groups) received 2 or 3 drugs; most common 2 drug combination - sedative (usually Midazolam) and opiate (usually Morphine). Median doses - Midazolam (both groups) 10 mg over 24 hours; Opiates: Morphine - cancer 15 $\mathrm{mg}$, non-cancer $10 \mathrm{mg}$; Diamorphine - cancer $12.5 \mathrm{mg}$, 